\title{
Correction to: Evaluation of leukocyte esterase test strips for rapid diagnosis of subclinical mastitis in dairy cows
}

\author{
Abdolah Mirzaei $^{1} \cdot$ Amirarsalan Khorsand $^{1} \cdot$ Abolfazl Hajibemani $^{2} \cdot$ Hassan Sharifiyazdi $^{1}$ (D)
}

Published online: 10 May 2019

(C) Springer-Verlag London Ltd., part of Springer Nature 2019

Correction to: Comparative Clinical Pathology 28(1): 151-156 https://doi.org/10.1007/s00580-018-2808-0

The affiliation of Abolfazl Hajibemani in the original published version of this article was incorrect. Instead of Tabriz University, it should have been University of Tabriz.

Publisher's note Springer Nature remains neutral with regard to jurisdictional claims in published maps and institutional affiliations.

The online version of the original article can be found at https://doi.org/ $10.1007 / \mathrm{s} 00580-018-2808-0$

Hassan Sharifiyazdi

sharifiy@shirazu.ac.ir

1 Department of Clinical Sciences, School of Veterinary Medicine, Shiraz University, P.O. Box 1731, Shiraz 71345, Iran

2 Department of Clinical Sciences, Faculty of Veterinary Medicine, University of Tabriz, Tabriz, Iran 